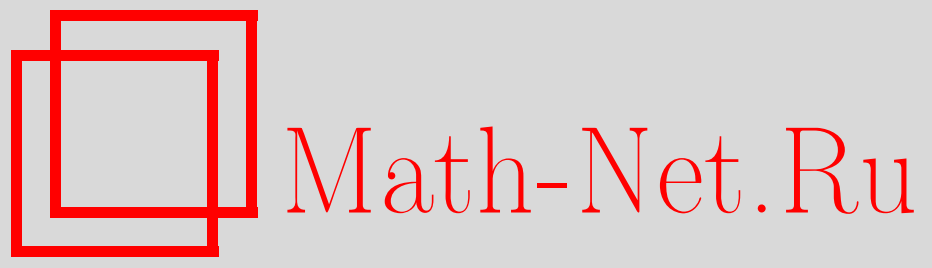

N. M. Mohamed, Monte Carlo sampling of Maxwell and Gaussian distributions using a single random number, Теория вероятн. и ее примен., 2013, том 58, выпуск 4, 818-823

DOI: https://doi.org/10.4213/tvp4545

Использование Общероссийского математического портала Math-Net.Ru подразумевает, что вы прочитали и согласны с пользовательским соглашением http://www . mathnet.ru/rus/agreement

Параметры загрузки:

IP : 52.87 .193 .239

26 апреля 2023 г., 16:05:06

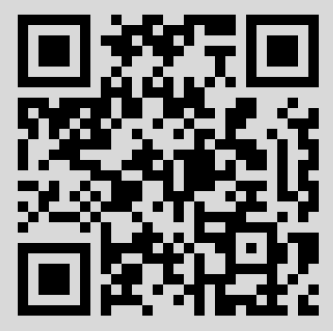


5. Royden H. L. Real Analysis. New York: Macmillan, 2nd ed., 1968.

6. Schäl M. 1993. Average optimality in dynamic programming with general state space. - Math. Oper. Res., 1993, v. 18, № 1, p. 163-172.

7. Serfozo $R$. Convergence of Lebesgue integrals with varying measures. - Sankhya: Ser. A, 1982, v. 44, №3, p. 380-402.

8. Ширяев А.Н. Вероятность. М.: МЦНМО, 2-е изд., 2012, 580 с.

Поступила в редакцию

17.V.2012

Исправленный вариант

15.V.2013

(c) 2013 г

MOHAMED N. M. A.*

\title{
MONTE CARLO SAMPLING OF MAXWELL AND GAUSSIAN DISTRIBUTIONS USING A SINGLE RANDOM NUMBER
}

\author{
Предложенная формула применяется к распределению Максвелла и \\ дает результаты с высокой точностью. \\ Ключевые слова и фразы: выборка Монте-Карло, распределение \\ Максвелла, гауссовское распределение.
}

1. Introduction. There are two basic methods of sampling in Monte Carlo method: the direct method and the rejection method [1], [2]. In direct method the random variable, $x$, is determined from the following equation:

$$
x=c^{-1}(r),
$$

where $c^{-1}(r)$ is the inverse function of the cumulative probability function $c(x)$ and $r$ is a random number uniformly distributed on $[0,1]$.

In order to apply the direct method, there are two conditions: 1) the probability density function (p.d.f.) can be integrated analytically and 2) the cumulative probability function must be invertible. If the p.d.f. does not satisfy these two conditions, the sampling usually is carried out using the rejection method. Some consider this method «crude» because random numbers are «wasted» unlike the direct method. It is particularly wasteful for «spiky» probability distribution functions [2]. Sampling from Gaussian distribution can be done by the Box-Muller-Wiener algorithm (BMW) [3]: if $r_{1}$ and $r_{2}$ are two random numbers uniformly distributed in the interval $[0,1]$, then the distribution can be sampled as

$$
x_{1}=\sqrt{2 \ln r_{1}} \sin \left(2 \pi r_{2}\right), \quad x_{2}=\sqrt{2 \ln r_{1}} \cos \left(2 \pi r_{2}\right),
$$

where $x_{1}$ and $x_{2}$ are random numbers distributed according to a Gaussian distribution of mean 0 and variance 1. Toral and Chakrabarti [4] showed that although the BMW algorithm is exact producing an unbiased Gaussian distribution and it is easily implementable on a vector computer, a serious disadvantage is that it is a rather slow algorithm. They reported that the rejection method is about 20 per cent faster than the pure BMW algorithm on scalar computers, but it has the disadvantage that it is not efficiently vectorizable. Other algorithms have been proposed [1] but they all share the unwanted feature of not being efficiently vectorizable. Toral and Chakrabarti mentioned an approximate method to generate Gaussian distributed random numbers as a more efficient method. More about nonuniform random variate generation is given in [5].

In general, Maxwell and Gaussian distributions with the p.d.f.'s

$$
\begin{aligned}
& p(x)=\frac{2 \sqrt{x}}{T^{3 / 2} \sqrt{\pi}} \exp \left(-\frac{x}{T}\right), \quad 0<x<\infty, \\
& p(x)=\frac{1}{\sigma \sqrt{2 \pi}} \exp \left(-\frac{x}{T}\right)\left[-\left(\frac{x-x_{1}}{\sqrt{2} \sigma}\right)^{2}\right], \quad-\infty<x<\infty,
\end{aligned}
$$

\footnotetext{
* Atomic Energy Authority, ETRR-2, Cairo, Egypt; e-mail: nmohamed@ictp.it
} 
respectively, can be sampled directly using the following equations [7]:

$$
x=T\left(\ln r_{1}-\ln r_{2} \cos ^{2}\left(\frac{\pi}{2} r_{3}\right)\right)
$$

for the Maxwell distribution, and

$$
x=x_{1}+\sqrt{-2 \ln r_{1}} \cos \left(2 \pi r_{2}\right)
$$

for the Gaussian distribution, where $r_{1}, r_{2}$, and $r_{3}$ are random numbers uniformly distributed in the interval $[0,1]$.

In this paper, an approximate formula is found for sampling Maxwell and Gaussian distributions using a single random number uniformly distributed in the interval $[0,1]$ as an efficient sampling method.

2. Approximate formula. It is found that the p.d.f. that has the form

$$
p(x)=k x^{a} e^{-x}, \quad-0.5 \leqslant a \leqslant 0.5, \quad 0 \leqslant x<\infty,
$$

where $k$ is the normalization factor, can be sampled using the approximate formula

$$
x \approx-C \ln \left(1-r^{1 /(a+1)}\right),
$$

where $C$ is a constant and $r$ is a random number uniformly distributed in $[0,1]$.

Also, it is found that the accuracy of this approximation depends on the value of $|a|$. As this value decreased, the accuracy increased, until $|a|=0$ which makes the two sides of the above equation equal (in this case $C=1$ ) which is the case of sampling from the exponential decay p.d.f. Therefore, the value of $a$ is limited between -0.5 and 0.5 to give a good accuracy.

The constant $C$ must satisfy the following condition:

$$
\text { Estimated mean }(\mathrm{EM}) \approx \text { True mean }(\mathrm{TM}),
$$

where

$$
\begin{gathered}
\mathrm{EM}=\frac{1}{N} \sum_{i=1}^{N} x_{i} \approx-\frac{C}{N} \sum_{i=1}^{N} \ln \left(1-r_{i}^{1 /(a+1)}\right), \\
\mathrm{TM}=\int_{0}^{\infty} x p(x) d x .
\end{gathered}
$$

Substitute (10) and (11) in (9) and solve for $C$ :

$$
C=\frac{\mathrm{TM}}{\mathrm{EM}_{F}}
$$

where

$$
\mathrm{EM}_{F}=-\frac{1}{N} \sum_{i=1}^{N} \ln \left(1-r_{i}^{1 /(a+1)}\right) .
$$

3. Verification. Solve (8) for the random number $r$ :

$$
r \approx\left(1-e^{-x / C}\right)^{a+1} .
$$

If we compare (14) with (1), we find that the right-hand side of (14) is the cumulative probability function:

$$
\int_{0}^{x} p\left(x^{\prime}\right) d x^{\prime} \approx\left(1-e^{-x / c}\right)^{a+1}, \quad 0 \leqslant x<\infty .
$$

Differentiate (15) and substitute in (7):

$$
k x^{a} e^{-x} \approx \frac{a+1}{C} e^{-x / C}\left(1-e^{-x / C}\right)^{a}, \quad-0.5 \leqslant a \leqslant 0.5, \quad 0 \leqslant x<\infty .
$$

Consider the following two examples for verification. 
$\mathrm{Ex} \mathrm{a} \mathrm{m} \mathrm{p} \mathrm{le} \mathrm{1.} a=0.5$. Consider the p.d.f.

$$
p(x)=1.1287 x^{1 / 2} e^{-x}, \quad 0 \leqslant x<\infty .
$$

The true mean of $p(x)$ is calculated numerically: $\mathrm{TM} \approx 1.5$.

By using (13) and putting $a=1 / 2$ with 10000 trials, $\mathrm{EM}_{F}$ is found: $\mathrm{EM}_{F}=1.27$.

Using (12), we find $C=1.18$. Substitute in (16):

$$
1.1287 x^{0.5} e^{-x} \approx 1.271 e^{-x / 1.18}\left(1-e^{-x / 1.18}\right)^{0.5} .
$$

Fig. 1 is a plot of the two sides of (18).

$\mathrm{Ex} \mathrm{a} \mathrm{m} \mathrm{p} \mathrm{le} \mathrm{2.} a=-0.5$. Now, consider the p.d.f.

$$
p(x)=\frac{1}{\sqrt{\pi}} x^{-1 / 2} e^{-x}, \quad 0 \leqslant x<\infty .
$$

By applying the above procedure to calculate $C$, we find $C=0.804$. Substitute in (16):

$$
\frac{1}{\sqrt{\pi}} x^{-0.5} e^{-x} \approx 0.622 e^{-x / 0.804}\left(1-e^{-x / 0.804}\right)^{-0.5} .
$$

The two sides of this equation are plotted and given in Fig. 2.

Figs. 1 and 2 show that the right-hand side of (16) can be considered as a good fitting function for the left-hand side. This function can be sampled using the direct method to obtain the formula given in (8).

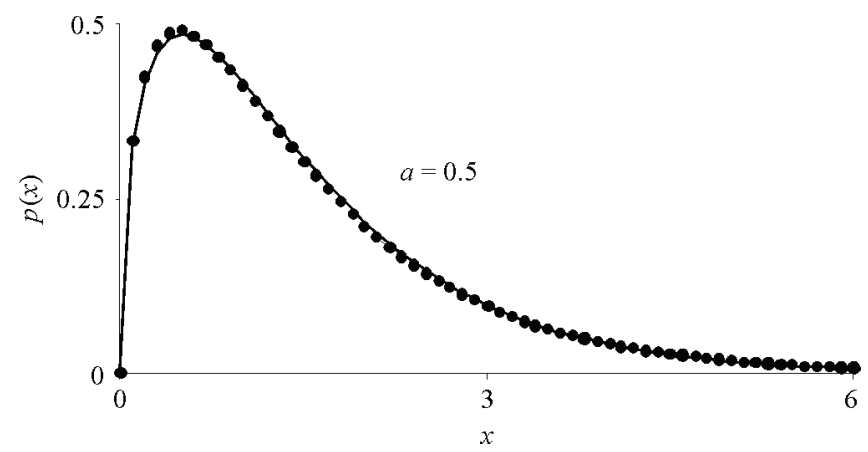

Fig. 1. The plot of the right-hand side (discrete circles) and the left-hand side (solid line) of (18).

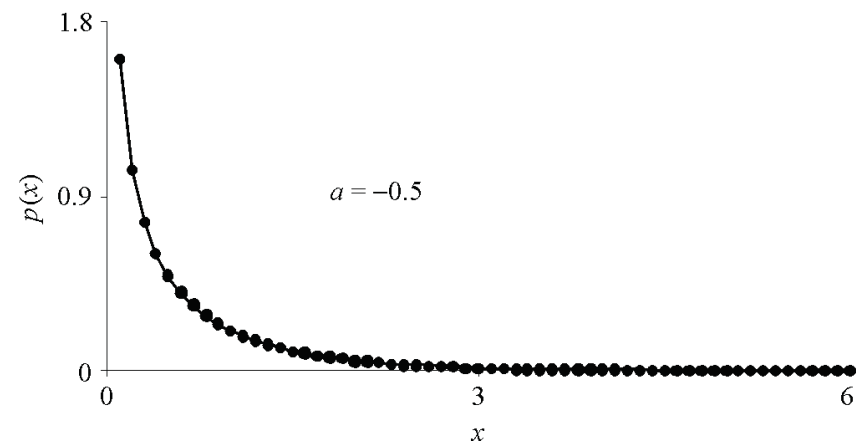

Fig. 2. The plot of the right-hand side (discrete circles) and the left-hand side (solid line) of (20). 


\section{Applications.}

4.1. Maxwell distribution. Consider the Maxwell p.d.f. given in (3). Let

$$
y=\frac{x}{T} \text {. }
$$

We find the p.d.f. as function of $y$ :

$$
p(y)=\frac{2}{\sqrt{\pi}} y^{1 / 2} e^{-y}, \quad 0 \leqslant y<\infty .
$$

Equality (22) has the same form as (17). It follows that $C=1.18$ and by substituting in (8) (after changing the «dummy» variable $x$ by $y$ ), $y$ can be sampled as

$$
y=-1.18 \ln \left(1-r^{2 / 3}\right) .
$$

Finally, substitute $(23)$ in $(21)$ to get $x$ :

$$
x=-1.18 T \ln \left(1-r^{2 / 3}\right) .
$$

50000 values for $x$ are selected using the random number $r$. The values are binned in about 40 bins. The calculated p.d.f. $f_{i}\left(x_{i}\right)$ is obtained by

$$
f_{i}\left(x_{i}\right)=\frac{n_{i}}{N w_{i}}
$$

where $n_{i}$ is the number of values in the $i$-th bin, $w_{i}$ is its width and $N$ is the total number of trails $\left(N=50000\right.$ in this case). Value of $x_{i}$ is calculated as the middle point between the boundaries of the bin $i$. Fig. 3 gives the $f_{i}\left(x_{i}\right)$ for this p.d.f. with its analytical expression for $T=1.667$. The figure shows that there is a good agreement between the $f_{i}\left(x_{i}\right)$ and the analytical expression of $p(x)$. Also Fig. 4 is a plot of the two sides of (16) for this example.

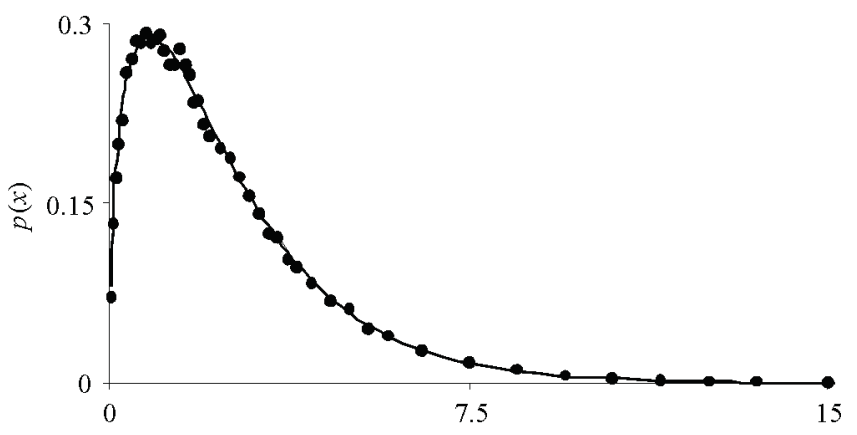

Fig. 3. The plot of the $f_{i}\left(x_{i}\right)$ (discrete circles) ${ }^{x}$ and $p(x)$ (solid line) for the p.d.f. $p(x)=$ $0.5244 x^{1 / 2} \exp (-x / 1.667)$.

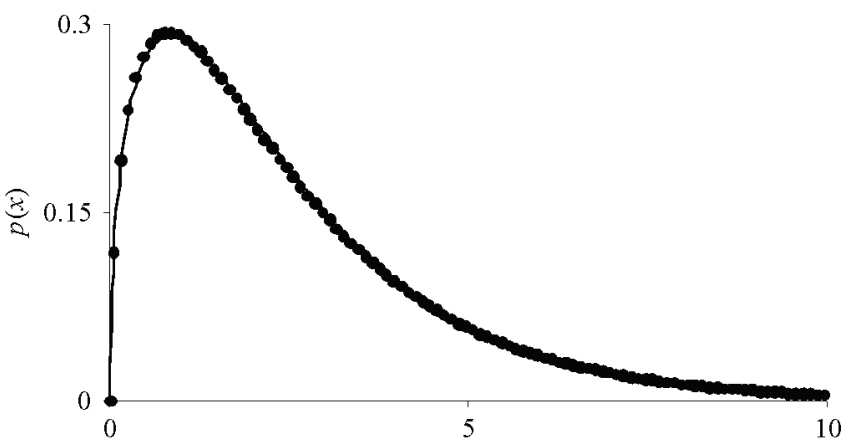

Fig. 4. The plot of the right-hand side (discrete circles) and the left-hand side (solid line) for the p.d.f. $0.5244 x^{0.5} e^{-x} \approx 0.7626 e^{-x / 1.967}\left(1-e^{-c / 1.967}\right)^{0.5}$. 
4.2. Gaussian distribution. Consider now the Gaussian p.d.f. given in (4): Let

$$
y=\left(\frac{x-x_{1}}{\sqrt{2 \sigma}}\right)^{2} .
$$

Noting that the range of $y$ will be $\left[x_{1}, \infty\right]$, we find

$$
p(y)=\frac{1}{\sqrt{\pi}} y^{-1 / 2} e^{-y}, \quad x_{1} \leqslant y<\infty,
$$

Formula (8) yields

$$
y=-C \ln \left(1-r^{2}\right)
$$

Here, $C=0.804$.

Substitute (28) in (26) and solve for $x$ :

$$
x= \pm 1.268 \sigma\left[-\ln \left(1-r^{2}\right)\right]^{1 / 2}+x_{1} .
$$

The sign of the right-hand side of (29) can be selected using a random number as discrete distribution or accept the two values for each trail.

Fig. 5 is a plot of the $f_{i}\left(x_{i}\right)$ (using 100000 trials, we accept the two values for each trail) and the analytical expression for a Gaussian p.d.f. with $\sigma=\sqrt{2}$ and $x_{1}=5$. Also there is a good agreement between the $f_{i}\left(x_{i}\right)$ and the analytical expression of $p(x)$. Fig. 6 is a plot of the two sides of (16) for this example.

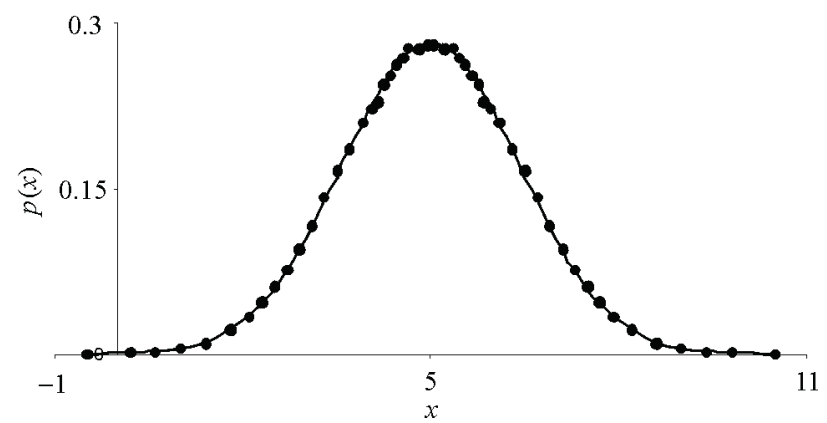

Fig. 5. The plot of the $f_{i}\left(x_{i}\right)$ (discrete circles) and $p(x)$ (solid line) for the normal p.d.f. $p(x)=0.282 \exp \left[-((x-5) / 2)^{2}\right]$.

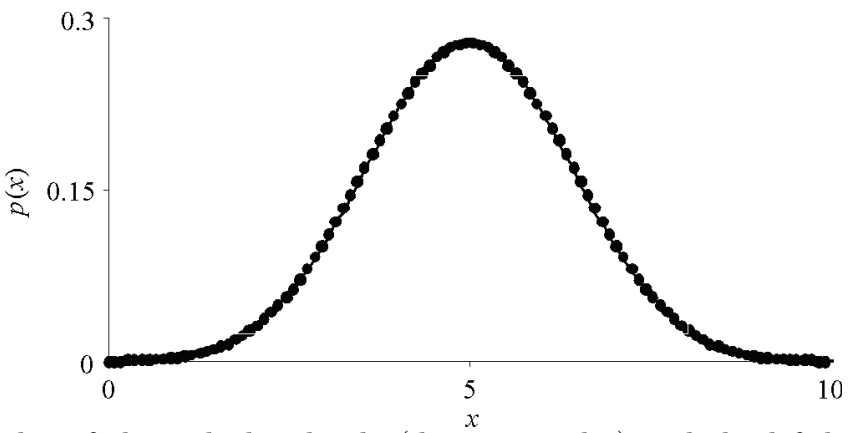

Fig. 6. The plot of the right-hand side (discrete circles) and the left-hand side (solid line) for the p.d.f. $-0.282 \exp \left(-u^{2}\right) \approx|0.297 u| \exp \left(-u^{2}\right)\left[1-\exp \left(-u^{2}\right)\right]^{-0.5}$, where $u=(x-5) / 0.558$.

5. Conclusion. An approximate formula given in (8) can be used for sampling probability density functions with the form given in (7) as an efficient sampling method. From (8), formulas (24) and (29) are developed to sample the Maxwell and Gaussian distributions, respectively, using a single random number. This method of sampling is verified and gives results with high accuracy. 


\section{REFERENCES}

1. Kalos M. H., Whitlock P.A. Monte Carlo Methods. New York: Wiley, 1986, 186 p.

2. Bielajew A.F. Fundamentals of the Monte Carlo Method for Neutral and Charged Particle Transport. Ann Arbor: Univ. of Michigan, 2001, 348 p.

3. Box G. E. P., Muller M. E. A note on the generation of random deviates - Ann. Math. Statist., 1958, v. 29, p. 610-611.

4. Toral R., Chakrabarti A. Generation of Gaussian distributed random numbers by using a numerical inversion method. - Comput. Phys. Comm., 1993, v. 74, № 3, p. 327-334.

5. Devroye L. Non-uniform Random Variate Generation. New York: Springer-Verlag, 1986, 843 p.

6. Brown F. B. Monte Carlo advances \& challenges. Lectures at the 2005 Frederic Joliot \& Otto Hahn Summer School on Nuclear Reactors (August 24-September 2, 2005, Karlsruhe, Germany).

Поступила в редакцию 